\title{
COMPARISON OF ROOTING SITUATIONS FOR SALAKHANI AND ZIVZIK POMEGRANATES UNDER DIFFERENT IBA DOSES
}

\author{
AL-JABBARI, K. H. ${ }^{1}-$ PAKYÜREK, M. $.^{1 *}-$ YAVIÇ, A. $^{2}$ \\ ${ }^{1}$ Department of Horticulture, Faculty of Agriculture, Siirt University, 56100 Siirt, Turkey \\ ${ }^{2}$ Department of Horticulture, Faculty of Agriculture, Yüzüncü Yll University, 65080 Van, Turkey \\ *Corresponding author \\ e-mail: mine.pakyurek@siirt.edu.tr \\ (Received 28 $8^{\text {th }}$ Jul 2019; accepted $31^{\text {st }}$ Oct 2019)
}

\begin{abstract}
Rooting performance of Salakhani, a local variety of Iraq and Zivzik (Punica granatum L.), a local pomegranate of Siirt, were compared in our study. For this purpose, the effect of different doses of indole butyric acid (IBA) $(0.00,1000,2000,4000,6000 \mathrm{mg} / \mathrm{L})$ on rooting was examined. Cuttings were kept in the rooting environment for five months and rooting rates, root number, root lengths, survival rates, shoot lengths, shoot and leaf number were determined. Salakhani were found to be the best cultivar only in terms of the root length, sprout length, shoot number and leaf number. Zivzik were found to be the best variety with regard to the other properties. IBA application of $4000 \mathrm{ppm}$ was found to be the best all the shoot number, leaf number and root length. The hormone dose of $6000 \mathrm{ppm}$ was found to be the most beneficial for survival and rooting rates. Application of $1000 \mathrm{ppm}$ was found to be the best dose among the doses of hormone only on account of root number.
\end{abstract}

Keywords: plant growth regulators, Punica granatum L., cutting production, vegetative growth, hormone effect

\section{Introduction}

Pomegranate is one of the first five important fruits together with fig, date, olive and grape which are old known cultivated plants. The domestication of pomegranate started 3000-4000 BC in the North of Iran and Turkey (Usanmaz et al., 2014). It is a perennial plant grown in tropical and subtropical regions (Schubert et al., 1999). Iran and the Himalayas of Northern India are the central origin of pomegranate. This fruit grows well in semi-arid temperate and subtropical climate and it is naturally grown in any climate with cool winter and hot summer. Pomegranate is deciduous in the subtropics and is evergreen in the tropical regions.

It is a species found in temperate forests that requires high temperatures in summer in order to reach full maturity and achieve commercial production (Melgarejo and Martinez, 1989). For most species of pomegranate, the suitable temperature degrees are between $21^{\circ} \mathrm{C}$ and $27^{\circ} \mathrm{C}$ during day-time and $15^{\circ} \mathrm{C}$ of night-time temperatures (Hartmann et al., 1997). It is naturally grown and is well adapted to the regional climate in Afghanistan, China, Morocco, Palestine, India, Iraq, Iran, Israel, Italy, Cyprus, Egypt, Syria, Saudi Arabia, Thailand, Tunisia, Turkey. Iran, Spain, Tunisia and Turkey are the countries exporting pomegranates (Özgüven and Y1lmaz, 2000). India is first in terms of pomegranate production and production area. When it comes productivity, Spain $(18.5 \mathrm{t} / \mathrm{ha})$ comes first, traced by USA $(18.3 \mathrm{t} / \mathrm{ha})$. On the other hand, Iran (60.000 t/year) is first in point of exports, chased by India (37.176 t/year) (Chandra et al., 2006, 2008; Chandra and Meshram, 2010; Silva et al., 2013). 
Pomegranate cultivation is done in different soil types, such as sand, gravel, clay and heavy clay soils. Optimal development of pomegranate is observed in deep, permeable, alkali and sandy loam soils. In Turkey, pomegranate cultivation can be done in all regions, except for very cold regions. Furthermore, pomegranate can withstand the lowest temperature range from $-10^{\circ} \mathrm{C}$ up to $-15^{\circ} \mathrm{C}$, while the temperature lower than $-20^{\circ} \mathrm{C}$ causes the death of the plant. Period of vegetative growth ranges between 180-215 days. In addition, the flowering period ranges between 50-75 days, and the fruit growth and development period ranges between 120-160 days (Onur, 1983).

Its fruit is rich in vitamins, iron, folic acid, potassium and polyphenol antioxidants, which are used to treat different diseases and pomegranate extract is used as an alternative method for the treatment of especially different types of cancer, such as breast cancer and prostate cancer, skin cancer, colon cancer, and lungcancer. Pomegranate extract includes seed oil and pomegranate juice, pomegranate peel, and different parts of the plant roots, bark and flowers (Kavakl1 et al., 2011). Several parts of pomegranate have the biological properties of extracts, which have been used in therapeutics, such as in the prevention of infection, inflammation, cancer, and in other applications (Miguel et al., 2010). Fruit juice is an excellent source of sugars, vitamins (B and C) and minerals, potassium, iron, antioxidants, polyphenols, and some parts of the pomegranate tree, such as leaves, immature fruits, fruit peel, flower buds are used inmedicinal applications and also for the tanning of leather. Wild pomegranate has a very tart flavor and is of a little value, it is used only as a souring factor. The doubleflowered pomegranate used for decorative purposes (non-fruitful) is grown in parks and ornamental gardens for its beautiful red flowers and for the beauty of its appearance (Raj and Kanwar, 2010). Recent studies suggest that pomegranate juice contains anticancer, antimicrobial, and antiviral components (Reddy et al., 2007; Kotwal, 2007; Schwartz et al., 2009).

The propagation of pomegranate is performed either sexually by seeds or by using the vegetative method (asexual) with cuttings and less frequently it is performed using layers, suckers or graftings (Hartmann et al., 1997; Melgarejo et al., 2008; Polat and Çalışkan, 2009). The propagation from cutting (cloning) is an easy, quick and economical method which produces a plant of the same characteristics as the mother plant and which is uniform in sprouting, comes into bearing and fruiting earlier than the seedling and does not need any new techniques in grafting, budding and layering. The success of this process depends on some factors such as the condition of the mother plant, the age of the plant, planting time, temperature, and rooting media (Frey et al., 2006). Cutting is the simple and successful method of pomegranate propagation with $15-20 \mathrm{~cm}$ in length and of the pencil size or bigger in diameter and the use of semihardwood or hardwood rooting hormone is possible in this method (Melgarejo et al., 2008; Saroj et al., 2008; Polat and Çalışkan, 2009). The cuttings collected at the end of February have a higher rooting potential than those collected at the beginning of October (Polat and Çalışkan, 2009). Grafting is one of the propagation methods which is used for varieties to be propagated of which there are barely specimens from which cutting can be obtained; this process should be conducted at specific times, in May or in July, although it can also be done at the end of the summer (with dormant buds) (Melgarejo and Martinez, 1992). Tissue culture (micropropagation), which is another method of vegetative reproduction of fruit crops, helps in overcoming problems of sexual propagation, producing new plants of the same characteristics with their parents, quick, and mass production of planting materials (El-Agamy et al., 2009). 
Aim of this study is to compare effects of the application of IBA growth hormone on sprouting and rooting situations of two local pomegranate varieties, Salakhani, in Halabja province in North of Iraq and Zivzik, in South East of Turkey. There is no experiment about either Salakhani or Zivzik varieties on rooting with cuttings until now. Therefore this study is unique and important to guide subsequent studies.

\section{Literature Research}

Melgarejo et al. (2008) reported that the application of exogenous auxins to pomegranate cuttings resulted in the increase of rooting percentages up to three folds. Owais (2010) stated that the application of rooting hormones can increase the rooting percentage of pomegranate cuttings at the rate of 49-73\%. Rooting is significantly increased by the addition of synthetic auxins (Hartman and Kester, 1983). Polat and Çalışkan (2009) revealed that some factors, such as the physiological conditions of the parent plant, cutting types, the dates of their taking and medium type, affect the rooting of pomegranate cuttings. They suggested that the cuttings collected at the end of February had a higher rooting potential than those taken at the beginning of October.

In other investigation accomplished under mist chamber by Singh (2014) it was shown that different concentrations of IBA had a significant effect on some growth characteristics of hardwood cuttings in Punica granatum L. It was noted that the maximum rooted percentage, root length, sprouted length and leaf number percutting were obtained at the $5000 \mathrm{ppm}$ dose of IBA, while the minimum value was reached in the control group. Alikhani et al. (2011) conducted an experiment to determine the effects of the kind of medium and the kind of pomegranate cuttings on the rooting ability and growth of cuttings under greenhouse conditions. In this experiment, two different medium cultures (sand/peat and sand) and three kinds of pomegranate cuttings (one bud, three buds, more than three buds) were used. At the end of the study, it was revealed that the effect of cutting type on leaf number was significant $(\rho<0.05)$. However, it was found out that the effects of medium and interaction between cutting type and medium type on leaf number were not so significant, additionally, the type of the cutting had an influence on leaf number. It was noted that the cutting type had a significant effect on shoot number. On the contrary, the effect of medium and interaction between cutting type and medium type on shoot number was not significant. In terms of raised bud numbers, the effect of medium and cutting type was not significant. However, the effect of cutting type on raised bud number and the effect of interaction between medium type and cutting type on raised bud number were significant. Eventually, the effect of medium and cutting types and the effect of interaction between them on root length were significant.

Abu-Zahra et al. (2013) examined in their study the application of exogenous auxins to ornamental plants such Rosemary, Hedera, Syngonium and Gardenia (all of them are difficult to root without using a rooting hormone) in six different concentrations of NAA (0, 1000, 2000, 3000, 4000 and 5000 ppm NAA). Result of their study showed that the highest rooting percentages as the number of roots, the best length, in comparison to the control treatment, were obtained with 3000 ppm NAA in Rosemary and Hedera cuttings, while the best results were obtained with 4000 and $1000 \mathrm{ppm}$ NAA in Gardenia and Syngonium cuttings, respectively. Adekola and Akpan (2012) realized an experiment to assess the effect of the application of two growth hormones, NAA and IBA, on sprouting and rooting behaviours of Nigerian (Jatropha). The growth regulator was applied by adopting the slow dip method (for $24 \mathrm{~h}$ ). In addition, the 
untreated replication was accepted as a control group. The results showed that there were no significant treatment differences in the survival percentage and sprouting behaviour of $J$. curcas. A slight selective response to the application of growth hormones was observed in terms of rooting behaviour, as IBA treated cuttings rooted better than the NAA-treated cuttings. However, the untreated cuttings gave the best performance for all the parameters assessed on the sprouting and rooting ability of J. curcas. Hence, the untreated cuttings can be used for the mass production of Jatropha since they are good propagating materials.

Sharma et al. (2009) executed an experiment to improve the rooting and reduce the mortality of rooted cuttings under field conditions. The results clearly indicated that the treatment of IBA $500 \mathrm{ppm}$ with Borax $1 \%$ produced the greatest root number and root length in semi-hardwood and hardwood cuttings of pomegranate. Consequently, the semi-hardwood and hardwood cuttings of pomegranate cultivars. Ganesh treated with IBA 500 ppm + Boron 1\%, IBA 300 ppm + Borax 2\% and IBA 5000 ppm gave 100\% survival of the rooted cuttings under field conditions. Babaie et al. (2014) investigated the effect of different IBA concentrations (control, 2000, 4000 and $6000 \mathrm{ppm}$ ) and the time of taking acutting (late June and early September) on the rooting growth and survival of $F$. Binnendijkii 'Amstel Queen' cuttings. Detected that at $6000 \mathrm{ppm}$ and $4000 \mathrm{ppm}$ of IBA and the time of cutting in early September, the highest percentage of rooting ranging from $100 \%$ to $96.66 \%$, respectively, the longest root length $(16.61 \mathrm{~cm})$ and the greatest number of roots were recorded (15.69 and 14.27, respectively). Whereas the greatest length of new shoots was obtained in the IBA concentration of $2000 \mathrm{ppm}$ and $4000 \mathrm{ppm}$ in late June, the maximum number of new leaves was obtained in the IBA concentration of $2000 \mathrm{ppm}$ and $4000 \mathrm{ppm}$, with the cutting taken in late June.

Ansari (2013) noticed in his testing that different media and pomegranate cutting separation dates had highly significant effects on rooting characteristics. If suitable media are used, a better cutting separation takes place at the end of they are in terms of a higher rooting percent and increasing root number (Singh, 2009; Janner, 2012; Young, 2012). Furthermore, among different media, vermiculite and its mix with sand were the best for a higher rooting percent and root number. A research actualized on five pomegranate varieties by Owais (2010) was determined all of them had root ability higher than $80 \%$ at 9000 ppm IBA treatment, and although the ability of generating roots was enhanced by IBA treatment, it seemed to be that much variability was related to the variety. Hardwood cuttings of pomegranate varieties seem to have a clearly higher root ability than those of semi-hardwood cuttings at different IBA levels for different pomegranate varieties.

Singh et al. (2011) carried out a search to study the effect of planting time and IBA (Indole Butyric Acid) on rooting and vegetative growth of pomegranate cuttings (Ganesh) with different concentrations of IBA 50, 100 and $200 \mathrm{ppm}$ (s.d) for $24 \mathrm{~h}$ and IBA 1000, 1500, and 2000 ppm (q.d) for 15 s, on December 15 and January 15, respectively. The results showed that there were significant differences between the time of plantation, IBA treatment concentrations and their interaction with regard to sprouting and last survival percentage of cuttings and statistically significant differences were observed between the dates of plantation and IBA concentrations applied with regard to the number of roots, length of the longest root and root weight characteristics, as well as significant variations between the time of plantation and growth regulator concentrations were observed with regard to the plant height. 
In another study succeeded in July, December and January by Kahlon (2007) it was shown that season and shoot part had a significant effect on the sprouting percentage and growth of pomegranate. Also, in that experiment was noted that the greatest sprouting was observed in January and the least one in July plantings and a much higher one was observed in January plantings. Furthermore, the sprouting percentage was the highest in the middle part when compared to the basal and sub-apical types of cuttings. Melgarejo et al. (2000) worked on the effect of 2000, 4000, 8000 and $12.000 \mathrm{ppm}$ indole butyric acid (IBA) concentrations and wounding at the cutting base in pomegranate. Results showed that IBA markedly increased the percentage of rooting (although not at all concentrations), with a high concentration of $12.000 \mathrm{ppm}$ producing the best results in the clones studied. Moreover, wounding carried out at the base of the cutting further increased the percentage of rooting in most of the clones studied.

Mehraj et al. (2013) achieved a trial to study the influence of IBA on the sprouting and rooting potential of (Bougainville spectabilis) stem cutting during the period from May to August, with different concentrations of Indole Butyric Acid (control, IBA in dust form, 500 ppm, 1000 ppm, 2000 ppm). The cuttings were soaked in IBA solution for $(24 \mathrm{~h})$ and the IBA dust was attached to the cutting just before the establishment in soil. They found out that IBA at $1000 \mathrm{ppm}$ resulted in most sprouting, rooting and a higher survival percentage of rooted cuttings along with a higher number of roots, sprout buds, maximum root length and diameter. Singh et al. (2015) conducted one another experiment under valley condition to study the effect of different growing conditions (two different conditions, namely, shade house and mist chamber) and various concentrations (control, 1000, 1500, and $2000 \mathrm{ppm}$ ) of IBA on the rooting and shooting of hardwood cutting of phalas (Grewia asetica L.) in the month of September. Result of the study showed the greatest success of hardwood cuttings in the mist chamber growing condition, while IBA 2000 ppm gave the highest success rate of cuttings in all aspects, such as rooting percentage, the length of shoot, the length of root, thickening of root and leaf sprouting in the shoot.

Singh et al. (2014), performed a search in the mist house to study the effect of different concentrations (control, 1000, 2000, 3000, 4000, $5000 \mathrm{ppm}$ ) of IBA on inducing rooting in stem cutting (softwood cutting) of Duranta erecta var. golden. Softwood cuttings of Duranta erecta var. golden were obtained from 2 to 4-year-old plants and $15 \mathrm{~cm}$ long cuttings with the apical part. They found out that IBA at $4000 \mathrm{ppm}$ resulted in the maximum percentage of rooted cuttings, followed by $5000 \mathrm{ppm}$ concentration of IBA and the minimum percentage of rooted cuttings was observed under control. Fouda and Schmidt (1995) informed the effect of different concentrations (500, 1000, and $2000 \mathrm{ppm}$ ) of IBA on root development in Rosa canica and Rosa rougosa leafy cuttings. They found out that IBA increased rooting percentage in Rosa canica, the maximum rooting percentage was achieved with the cuttings collected at the beginning of June and treated with $1000 \mathrm{ppm}$ IBA.

Ghosh et al. (1988) declared the effect of NAA and IBA on adventitious root formation in the stem cutting of pomegranate (Punica granatum L.) under intermittent mist. They found that IBA was more effective than NAA in inducing rooting of hardwood, semi-hardwood and softwood cutting. IBA at $5000 \mathrm{ppm}$ resulted in the maximum rooting success $(83.33 \%)$, but at higher concentration $(10.000 \mathrm{ppm})$, a greater number of roots and increased root length were recorded. The greatest rooting success was obtained with hardwood cutting. Hedge and Sulikeri (1989) studied the effect of indole butyric acid (IBA) on the rooting in the air layers of pomegranate. In the trials 
with cv. Jyothi, mature shoots were treated with IBA at 250-1500 ppm and air layered between June and August. Rooting increased with IBA concentration from $84.38 \%$ at $250 \mathrm{ppm}$ to $93.75 \%$ at $1500 \mathrm{ppm}$ and $68.75 \%$ in the control.

Hansen (1986) carried out a research under the controlled greenhouse condition for 13 weeks to study the effects of cutting position and stem length in Schefflera arboricola and to develop propagation technique to obtain a fast and uniform root formation. Eight cuttings from the sub-apical to basal regions were excised from each stock plant. The stem length above the node was the same for all cuttings, whereas the stem length below the node was cut to different lengths, ranging from 0.5 to $3.0 \mathrm{~cm}$. He found that cuttings from sub-apical positions rooted more slowly, produced fewer roots and had a lower rooting percentage than cuttings from the more basal regions, furthermore, the number of roots and rooting percentage increased with the length of the stem below the node.

\section{Materials and Methods}

\section{Plant Material}

This study was carried out in $2015-2016$, at $25^{\circ} \mathrm{C}$ room conditions in the Physiology Laboratory of the Department of Horticulture, Faculty of Agriculture, Siirt University in Turkey. In this experiment, a private orchard of pomegranate Salakhani and Zivzik were selected, and the plant age ranged between 20-25 years for Salakhani and 20-25 years for Zivzik and trees were selected on the basis of their uniformity in appearance, growth habits and vigour. Salakhani variety is a local pomegranate genotype grown naturally, specifically in Halabja province, Northern of Iraq, and Zivzik variety is considered to be one of the local varieties available in Siirt province in the Southeast of Turkey. Cuttings of Salakhani variety were collected from their natural area in Halabja and cuttings of Zivzik variety were collected from Zivzik Village in Şirvan district of Siirt at the beginning of the Spring.

\section{Preparation of Experiment}

Our experiment was conducted to study effect of different concentrations of (IBA) Indole Butyric Acid on rooting percentage, survival percentage, branches number, sprout length, root number, root length and leaves number of pomegranate cuttings of Salakhani cultivars and Zivzik cultivars, during the period from May to August. Five treatments (control, $1000 \mathrm{ppm}, 2000 \mathrm{ppm}, 4000 \mathrm{ppm}$ and $6000 \mathrm{ppm}$ ) were applied in the experiment with three replications. $25 \mathrm{~cm}$ in lenght cuttings were obtained from $1 \mathrm{~m}$ in lenght cuttings. 10 cuttings were used per treatment in a pot with three replications. Therefore, there were 30 cuttings in each treatment and 300 cuttings in total were used in the experiment for both cultivars (Salakhani and Zivzik variety). The data on the root and shoot characteristics were collected five months after planting. Perlite and peatmoss were used as rooting media. A mix of peatmoss and perlite at a ratio 1-1 was used for both varieties.

Hormone solutions were prepared by dissolving 0.1, 0.2, 0.4 and $0.6 \mathrm{~g}$, respectively, of IBA pure powder and diluting with $50 \%$ alcohol (ethanol), and adding $50 \%$ pure water to make $100 \mathrm{ml}$ of each concentration. Pure water and alcohol were used as control treatment. Preparation process of cuttings was conducted in the laboratory of the Department of Horticulture, Agriculture Faculty, Siirt University. Vigorous shoots from 
the previous year of grown and healthy pomegranate trees were used for obtaining the cuttings, and the cuttings of a standard size were washed with tap water. Subsequently, a sharp knife was used in the preparation of cuttings for the experiment to avoid the injury of the cutting. The cuttings of uniform lengths, approximately $15 \mathrm{~cm}$ in length, were taken in the month of February when the plants are dormant with wounding by making two opposite longitudinal incisions at the base of each cutting. At least three nodes were included in each cutting. The bottom of the cuttings was treated with hormone of Indole Butyric Acid (IBA) at different concentrations. Basal 1-1.5 cm portion of the cutting was dipped in the growth regulator solution of IBA for 10 seconds (q.d) and immediately inserted in the media at a slight angle to the vertical, to a depth of $10-11 \mathrm{~cm}$ (as shown in Figure 1).
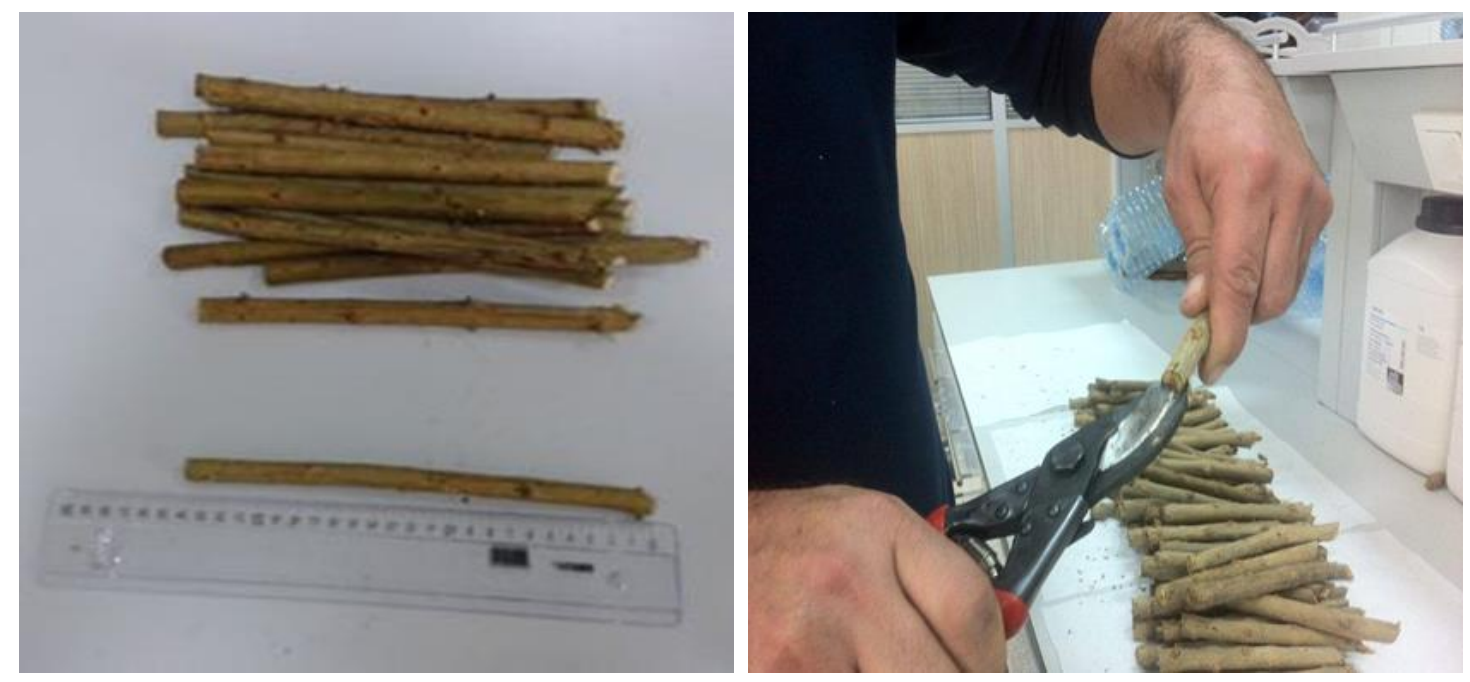

Figure 1. Preparing of the cuttings

\section{Experimental Procedures and Statistical Calculations}

Parameters obtained from our experiment were measured in the laboratory of the Department of Horticulture, Siirt University. These traits included the rooting percentage, number of roots per cutting, survival cutting rate, number of shoots per cutting, root length $(\mathrm{mm})$, sprout length $(\mathrm{mm})$ and the number of leaves per cutting, which were recorded at the termination of the experiment (Figure 2) after five months, at harvesting early in August. The roots were examined by lifting cuttings carefully from the rooting media and washing them with tap water. The measurement process was conducted by a tape-measure. The data were collected from all of the cuttings and then the mean value was calculated. Experimental design used which was factorial design in randomised plots. The treatment in each experiment had three replicates and each pot (container) consisted of 10 cuttings. The results of the experiment were statistically analysed and the means were compared using Duncan's Multiple Range Test at the level of 0.05. All analyses were performed by JMP Version 5.0.1 statistical software and letterings were shown in graphs (Figures 3 and 4) and Table 1. 


\section{Results and Discussions}

The following findings were obtained in our rooting study. When the data on rooting percentage were examined, there was found $1 \%$ statistical significance in terms of varieties and hormone doses. While 5\% significance level in terms of IBA type hormone interactions.

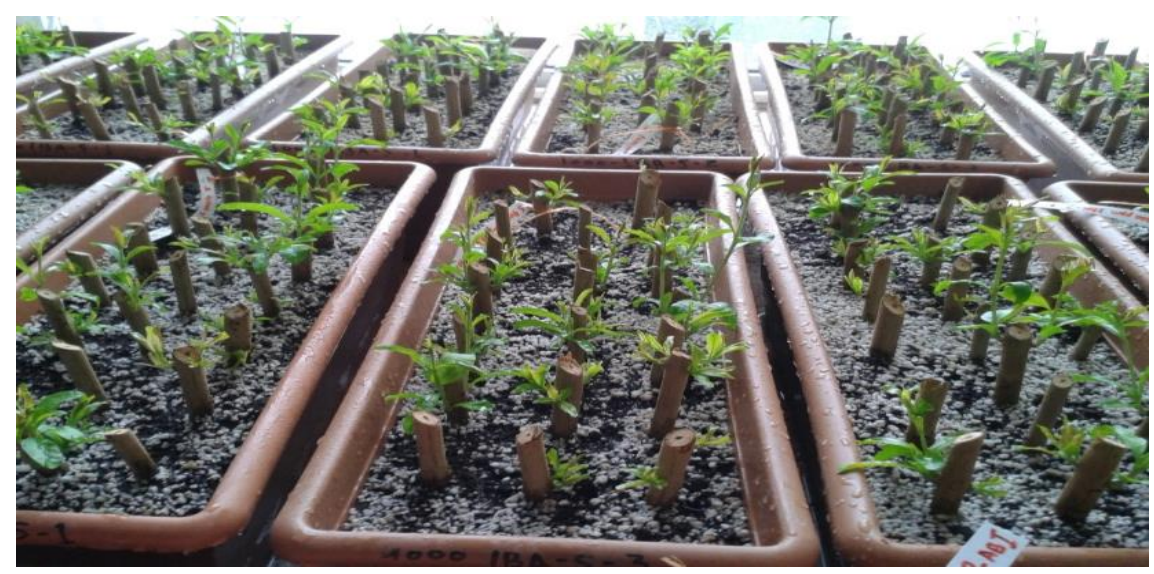

Figure 2. A view of the experiment

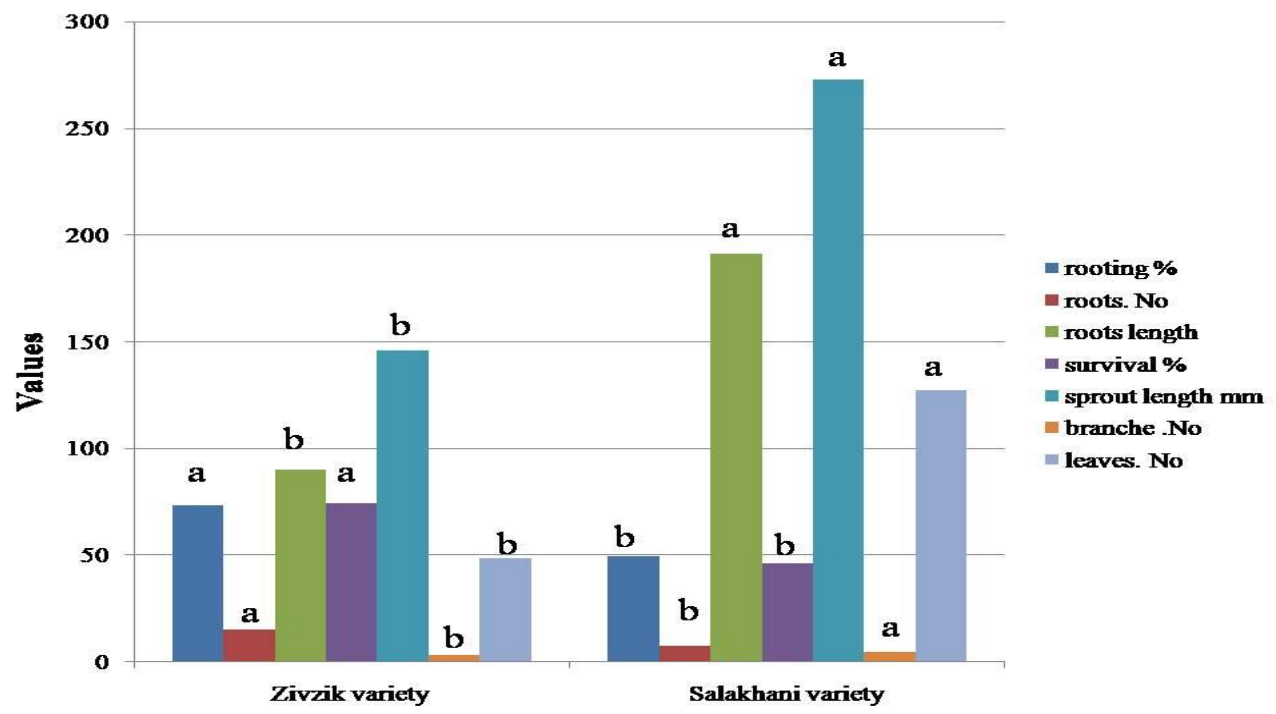

Figure 3. Effect of different IBA treatments on rooting forms of Zivzik and Salakhani varieties. *Letterings were obtained from statistical data: $P<0.001$; $0.05 \%$ level of probability using LSD

\section{Rooting Findings}

\section{Rooting Percentage (\%)}

Highest percentage of rooting $(73 \%)$ was observed in Zivzik variety, Siirt native. While, Salakhani variety was the second and last one with the rooting percentage of $49 \%$, respectively (Figure 3). Among the hormone doses used, the highest percentage (72\%) of the hormone dose was a demonstrated at $6000 \mathrm{ppm}$, while, the control group was the second one with $67 \%$ rooting percentage (Figure 4 ). The hormone dose group 
with the lowest percentage of rooting (43\%) was the $4000 \mathrm{ppm}$ dose group. The highest (93\%) rooting percentage in the variant IBA hormone interactions was found to be related to the $6000 \mathrm{ppm}$ dose applied to Zivzik variety, while the lowest value $(23 \%)$ was obtained in the case of Salakhani variety with the $4000 \mathrm{ppm}$ dose of IBA (Table 1). Hormone use is more effective in clones, especially in rooting fractions (Melgarejo et al., 2000). However, that the untreated stem cuttings had the best performance in terms of rooting of (Punica granatum L.) Salakhani variety could be due to the fact that growth hormones may not be the essential major factor influencing root induction in that variety. The rooting of cuttings may be influenced more by other factors such as the physiological age of cuttings and the status of rooting media in terms of aeration and drainage properties as stated by Narin and Watna (1983). In this experiment, the highest hormone concentration was the most positive effective dose in terms of the rooting percentage. This result is in conformity with the findings of Melgarejo et al. (2000) and Singh et al. (2015) who reported that the highest percentage of rooting was observed due to the increased hormone concentration. Similar results were also reported by Mehraj et al. (2013), Fouda and Schmidt (1995). Owais (2010) indicated that IBA had a significant effect on the rooting. Abu-Zahra et al. (2013) found different results, so it is thought that the hormones used are derived from different types.

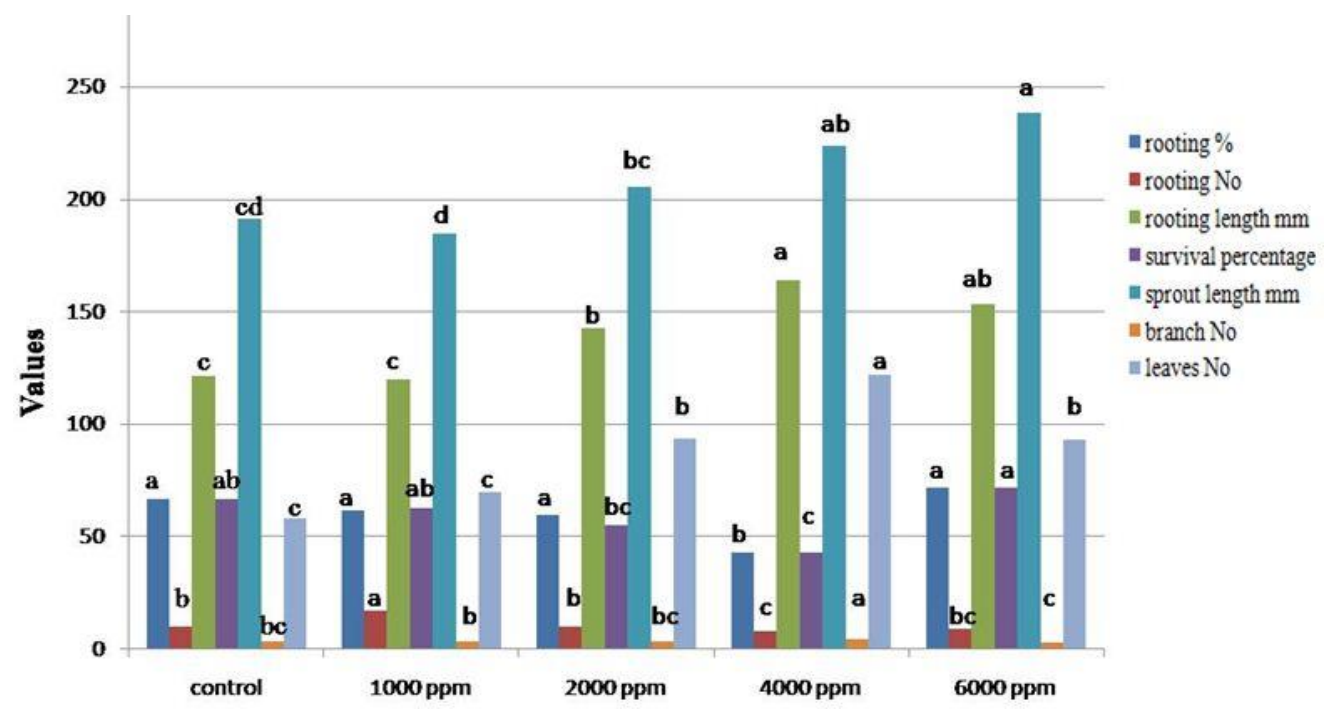

Figure 4. Effect of IBA concentrations on survival performance and growth of the cuttings.

*Letterings were obtained from statistical data: $P<0.001$; $0.05 \%$ level of probability using LSD

\section{Number of Root}

When the measurements of rooted number were examined for Zivzik and Salakhani pomegranate, it was observed that Zivzik variety increased the number of roots up to two folds compared to Salakhani variety, whereas, the values obtained for both cultivars in the root number percentage were as follows: 14.7 for Zivzik variety and 7.03 for Salakhani variety (Figure 3). Considering the root characteristics such as the number of roots per cutting for both varieties (Salakhani and Zivzik cultivars), it was determined that Zivzik cultivars produced the maximum root number and that the IBA treatment at $1000 \mathrm{ppm}$ produced the highest root number (17.06) and the lowest number of roots (7.93) was determined with IBA at 4000 ppm (Figure 4). When the table is examined 
according to the IBA type hormone interactions in terms of the number of rooted seedlings, it is seen that the number of seedlings rooted at the highest level (27.08) is in Zivzik variety at $1000 \mathrm{ppm}$. In contrast, the lowest number (5.44) of seedlings rooted is in Salakhani variety, with 4000 ppm of IBA (q.d) treatment (Table 1). From the present study, it is revealed that soaking the cutting in IBA solution increases the number of rootson cuttings due to the rooting ability of IBA. Hartmann et al. (1997) stated that the concentration of auxins substantially higher than that normally found in plant tissues may play an inhibitory role for the growth and root formation. Ramdayal et al. (2001) and Gupta et al. (2002) also found the maximum number of rootsat $1000 \mathrm{ppm}$ IBA. The findings related to the number of rooted seedlings were found to be parallel with the findings of Ghosh et al. (1988) who applied doses of 5000-10.000 ppm, Hegde and Sulikeri (1989) who applied 250-1500 ppm IBA and Mehraj et al. (2013) who used doses of 500-1000 and $2000 \mathrm{ppm}$. The difference in regard to the findings of Abu-Zahra et al. (2013) could be attributed to the difference of hormones used.

Table 1. Effect of the interaction among IBA doses and vegetative growth of the cuttings

\begin{tabular}{c|c|c|c|c|c|c|c|c}
\hline Cultivars & $\begin{array}{c}\text { hormone } \\
\text { doses }\end{array}$ & $\begin{array}{c}\text { rooting } \\
\text { rate }(\%)\end{array}$ & roots number & $\begin{array}{c}\text { roots length } \\
(\mathbf{m m})\end{array}$ & $\begin{array}{c}\text { survival rate } \\
(\%)\end{array}$ & $\begin{array}{c}\text { shoot } \\
\text { length }(\mathbf{m m})\end{array}$ & shoot number & $\begin{array}{c}\text { leaves } \\
\text { number }\end{array}$ \\
\hline \multirow{5}{*}{ Zivzik } & 0 & $0.67 \mathrm{BC}$ & $13.59 \mathrm{~B}$ & $89.08 \mathrm{D}$ & $0.67 \mathrm{BC}$ & $110.47 \mathrm{G}$ & $3.13 \mathrm{CD}$ & $23.03 \mathrm{G}$ \\
& 1000 & $0.73 \mathrm{~B}$ & $27.08 \mathrm{~A}$ & $84.79 \mathrm{D}$ & $0.77 \mathrm{AB}$ & $128.69 \mathrm{FG}$ & $3.17 \mathrm{CD}$ & $39.37 \mathrm{FG}$ \\
& 2000 & $0.67 \mathrm{BC}$ & $12.74 \mathrm{BC}$ & $98.91 \mathrm{D}$ & $0.70 \mathrm{~B}$ & $148.51 \mathrm{EF}$ & $2.58 \mathrm{D}$ & $49.76 \mathrm{EFG}$ \\
& 4000 & $0.63 \mathrm{BC}$ & $10.42 \mathrm{CD}$ & $100.31 \mathrm{D}$ & $0.63 \mathrm{BC}$ & $162.83 \mathrm{DE}$ & $3.17 \mathrm{CD}$ & $71.73 \mathrm{DE}$ \\
& 6000 & $0.93 \mathrm{~A}$ & $9.68 \mathrm{D}$ & $76.50 \mathrm{D}$ & $0.93 \mathrm{~A}$ & $177.48 \mathrm{D}$ & $2.70 \mathrm{D}$ & $56.38 \mathrm{EF}$ \\
\hline \multirow{5}{*}{ Salakhani } & $0.67 \mathrm{BC}$ & $7.05 \mathrm{EF}$ & $153.98 \mathrm{C}$ & $0.67 \mathrm{BC}$ & $273.01 \mathrm{AB}$ & $3.68 \mathrm{BC}$ & $93.94 \mathrm{D}$ \\
& 1000 & $0.50 \mathrm{C}$ & $7.03 \mathrm{EF}$ & $155.84 \mathrm{C}$ & $0.50 \mathrm{CD}$ & $241.50 \mathrm{C}$ & $4.31 \mathrm{~B}$ & $100.96 \mathrm{CD}$ \\
& 2000 & $0.53 \mathrm{C}$ & $7.16 \mathrm{EF}$ & $186.98 \mathrm{~B}$ & $0.40 \mathrm{DE}$ & $262.62 \mathrm{BC}$ & $4.28 \mathrm{~B}$ & $137.70 \mathrm{~B}$ \\
& 4000 & $0.23 \mathrm{D}$ & $5.44 \mathrm{~F}$ & $227.69 \mathrm{~A}$ & $0.23 \mathrm{E}$ & $285.55 \mathrm{AB}$ & $5.44 \mathrm{~A}$ & $177.44 \mathrm{~A}$ \\
& 6000 & $0.50 \mathrm{C}$ & $8.47 \mathrm{DE}$ & $230.76 \mathrm{~A}$ & $0.50 \mathrm{CD}$ & $300.23 \mathrm{~A}$ & $3.65 \mathrm{C}$ & $130.19 \mathrm{~B}$ \\
\hline
\end{tabular}

\section{Length of Root ( $\mathrm{mm}$ )}

While the highest root length $(191.05 \mathrm{~mm})$ was determined in the seedlings belongs to Salakhani variety, Zivzik seedlings were the lowest one with the length of $89.92 \mathrm{~mm}$ (Figure 3). When the effects of hormone doses on root length were examined, it was found out that the longest roots $(164 \mathrm{~mm})$ were obtained at dose of $4000 \mathrm{ppm}$, whereas the lowest one $(120.32 \mathrm{~mm}$ ) was obtained at dose of $1000 \mathrm{ppm}$ (Figure 4). At the same time, the control group without hormone treatment had longer lengths $(121.53 \mathrm{~mm})$ than the $1000 \mathrm{ppm}$ dose group (Figure 4). Based on the analysis of variance of the effect of IBA type hormone interactions on root lengths, the highest root length values (230.76 $\mathrm{mm}$ ) compared to other subjects were obtained in Salakhani variety with 6000 ppm IBA hormone (q.d) treatment, while the lowest root length values were obtained in Zivzik variety with $6000 \mathrm{ppm}$ hormone dose (Table 1). Statistical significance at the 1\% significance level was found in all subjects. The findings of Abu-Zahra et al. (2013) 
were different, which was due to the differences in the hormones used. The findings of Hartman and Kester (1983) who indicated that rooted seedlings increased significantly; Owais (2010) and Sharma et al. (2009) who found that the longest roots were derived from hormone-containing plants; Singh et al. (2011) and Ghosh et al. (1988) who identified the statistical differences between practices are similar to the findings in this study.

\section{Survival Cutting Rates}

The highest value (74\%) in terms of the survival rate was obtained from Zivzik variety. Whereas, the survival rate value measured in Salakhani variety used in the experiment was determined to be $46 \%$ as shown in Figure 3. Parallel results between the rooting rates and survival cutting rates were determined. When the effects of the hormones used in different doses on survival rates were examined, it was found that $6000 \mathrm{ppm}$ of hormone application provided the highest survival rates with $72 \%$, the control group (T0) was the second with $67 \%$ survival rates value while $4000 \mathrm{ppm}$ hormone dose application was the last (Figure 4). When the values of the IBA type hormone interaction were examined in terms of the survival rates, it was determined that the highest value (93\%) belonged to Zivzik variety with IBA at $6000 \mathrm{ppm}$. The interaction of Salakhani variety control group was better than other interactions. It is observed that Salakhani variety and 4000 ppm hormone dose interaction was in the last place with the value of $0.23 \%$ survival rates (Table 1 ).

\section{Length of Sprout ( $\mathrm{mm})$}

The highest value of sprout length $(272.58 \mathrm{~mm})$ was found in Salakhani variety and the lowest value $(145.59 \mathrm{~mm}$ ) was found to belong to Zivzik variety (Figure 3). When the effects of hormone doses on sprout length were examined in Zivzik and Salakhani varieties, it was found that among the hormone doses applied $6000 \mathrm{ppm}$ dose gave the highest $(238.85 \mathrm{~mm})$ sprout length and IBA at $1000 \mathrm{ppm}$ hormone dose gave the lowest $(185.09 \mathrm{~mm})$ sprout length (Figure 4). Among the IBA type hormone interaction, the highest sprout length $(300.23 \mathrm{~mm})$ was determined in Salakhani variety with IBA at $6000 \mathrm{ppm}$ and the lowest sprout length value $(110.47 \mathrm{~mm})$ was determined in Zivzik variety without hormone treatment (control group) as shown in Table 1.

\section{Number of Shoot}

It was determined that the average number of shoot in Salakhani variety (4.27) was higher than in Zivzik variety with 2.95 (Figure 3). According to the effects of hormone doses on shoots number, it was found out that the value belonging to $4000 \mathrm{ppm}$ hormone dose application (4.31) was higher than the values of other hormone doses. The lowest shoots number (3.18) was found in $6000 \mathrm{ppm}$ application (Figure 4). The shoots number of Salakhani variety observed in the hormone and variety interactions is superior to Zivzik variety. When the interactions were examined, the highest average value of shoots number (5.44) was obtained in Salakhani variety with the $4000 \mathrm{ppm}$ IBA hormone dose and the lowest value of shoot number (2.58) was obtained in Zivzik variety with $2000 \mathrm{ppm}$ (Table 1). Especially, the number of shoots and survival rates increased with the use of hormones in parallel with the findings of Janick (1972) and Hartmann and Kester (1983) who determined that the use of natural hormones increases the survival percentage as well as all vegetative developments in seedlings. 


\section{Number of Leaves}

When the varieties and hormone doses were examined in terms of the number of leaves, it was determined that the highest leaf number average value (127.05) was obtained from Salakhani variety and the lowest leaf number average value (48.05) was obtained from Zivzik variety (Figure 3). It was noted that the hormone dose of $4000 \mathrm{ppm}$ had the highest mean leaf number value (122.09) and the control value was the lowest value of the mean leaf number (58.48) (Figure 4). It has been determined that the leaf number is influenced by the variety and hormone interaction but not statistically significant. However, the highest leaf number average value $(177.44 \mathrm{~mm})$ was obtained from the interaction of Salakhani variety with IBA at 4000 ppm (q.d) treatment and the lowest value $(23.03 \mathrm{~mm})$ was obtained from Zivzik variety without hormone treatment (control treatment) (Table 1). Babaie et al. (2014) who performed similar studies and used IBA as a hormone reported that the largest number of leaves was available at doses of 2000 and $4000 \mathrm{ppm}$. Mehraj et al. (2013) found that the maximum vegetative growth was achieved with 1000 ppm of IBA.

Furthermore, more adventitious roots were observed on the pomegranate seedlings belonging to Zivzik variety. Meanwhile, strong and thick roots were observed on the pomegranate seedling of Salakhani variety which was more when compared to Zivzik cultivars. Moreover, the period required for the first sprouting of Salakhani variety ranged between 10-11 days. Whereas, the period required for the first sprouting of Zivzik variety reached 12-13 days. The above-mentioned period was considered to be the period between the days of planting the cutting to the day of sprouting the first bud on the cutting.

\section{Conclusion}

Upon examining sprouting and rooting behaviour in stem cuttings, highly contrasting responses to IBA addition were indicated among various concentrations of IBA, each variety had superiority to the other one in different aspects. Zivzik variety had a higher value of rooting number, rooting percentage and survival percentage than Salakhani variety. Salakhani variety had a higher value of root length, sprout length, shoots number and the number of leaves than Zivzik variety pomegranate. The highest dose of hormone $(6000 \mathrm{ppm})$ was found to be the most effective on rooting percentage, survival percentage and sprout length, while $4000 \mathrm{ppm}$ was found to be the most effective on root length, shoots number and the number of leaves. The $1000 \mathrm{ppm}$ dose was determined to significantly increase the root number compared to other doses. Regarding to the interaction effect of IBA doses, it was shown that the best performance in terms of rooting percentage, survival percentage, root length and sprout length was observed at the $6000 \mathrm{ppm}$ dose of IBA, whereas $4000 \mathrm{ppm}$ was found to be the most effective on shoots number and leaves number. The $1000 \mathrm{ppm}$ dose was determined to significantly increase root number compared to other doses. Hence, it can be concluded from the present experiment that the higher concentrations of IBA $(6000 \mathrm{ppm})$ and (4000 ppm) positively affect the sprouting and rooting ability in the stem cuttings of pomegranate $\mathrm{cv}$. Zivzik and Salakhani. In contrast, the optimum IBA concentration for the number of roots per cutting was found to be $1000 \mathrm{ppm}$ (Shoots and roots of the cuttings rooted in different hormone doses are given in Figure 5 and Figure 6). Based on the findings of current investigation, the results have proved that Zivzik variety gives better results than Salakhani variety in terms of rooting percentage, survival percentage 
and roots number in Turkey environmental conditions. From the results obtained in the present experiment and discussion, from the economic point of view, it can be concluded soaking the cut stem on 1000 ppm IBA solution for 10 second (q.d) before the establishment of the stem cuttings show maximum result in terms of root number was obtained at the $1000 \mathrm{ppm}$ dose of IBA and we recommend using $1000 \mathrm{ppm}$ of IBA, which will provide a significant increase in root number compared to other doses. In conclusion, pomegranate cuttings with different doses of IBA were successfully rooted in our study. As it is known, pomegranate is produced without vaccination. Therefore, it is important that pomegranate seedlings can be reproduced quickly and rapidly with cuttings. Because of this reason, further studies also can be done using different hormones and their doses to obtain the best sprouting and rooting results for cuttings of both Salakhani and Zivzik variety.
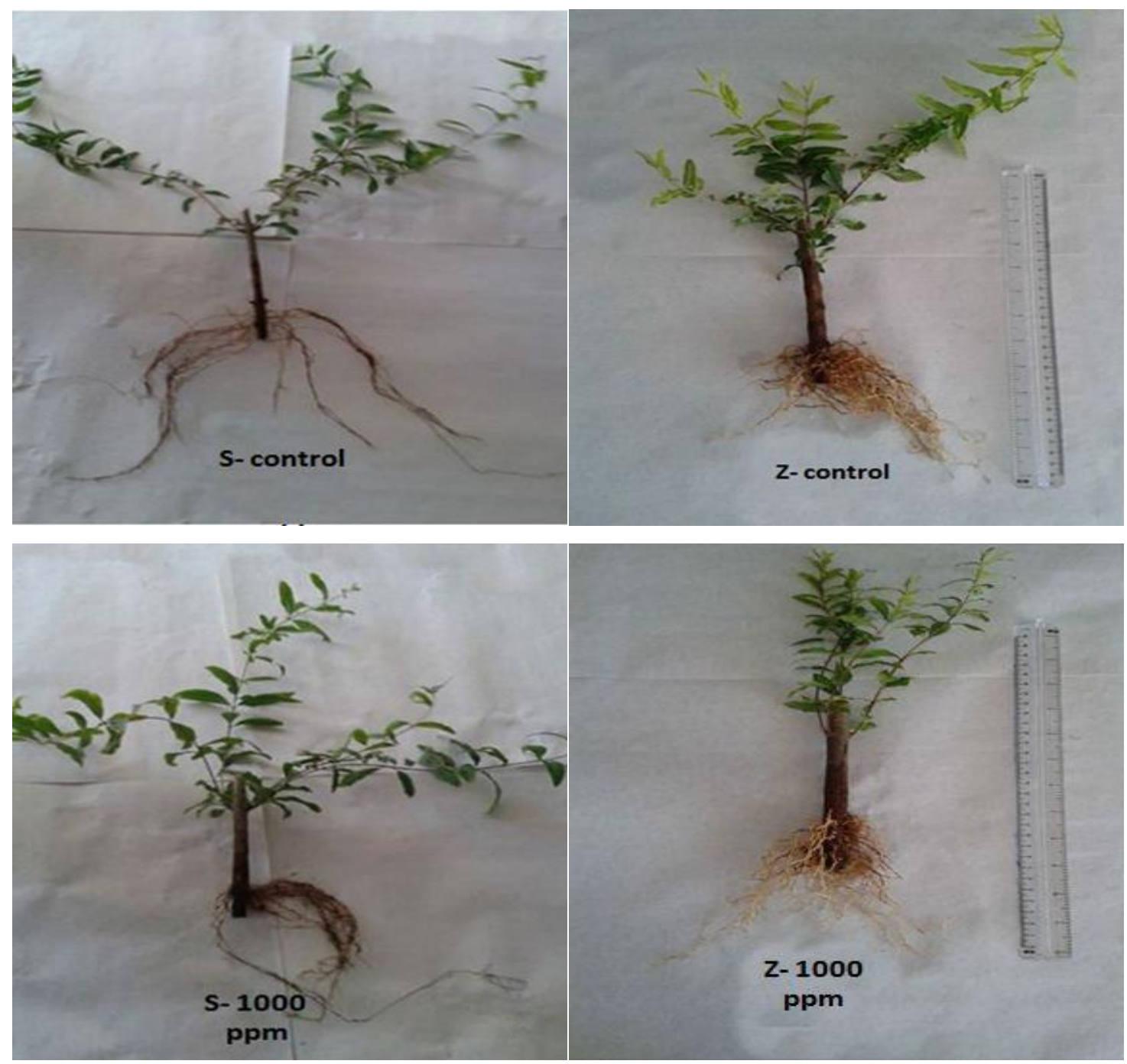

Figure 5. Root and shoot views of the cuttings (Control\&1000 ppm IBA dose). 

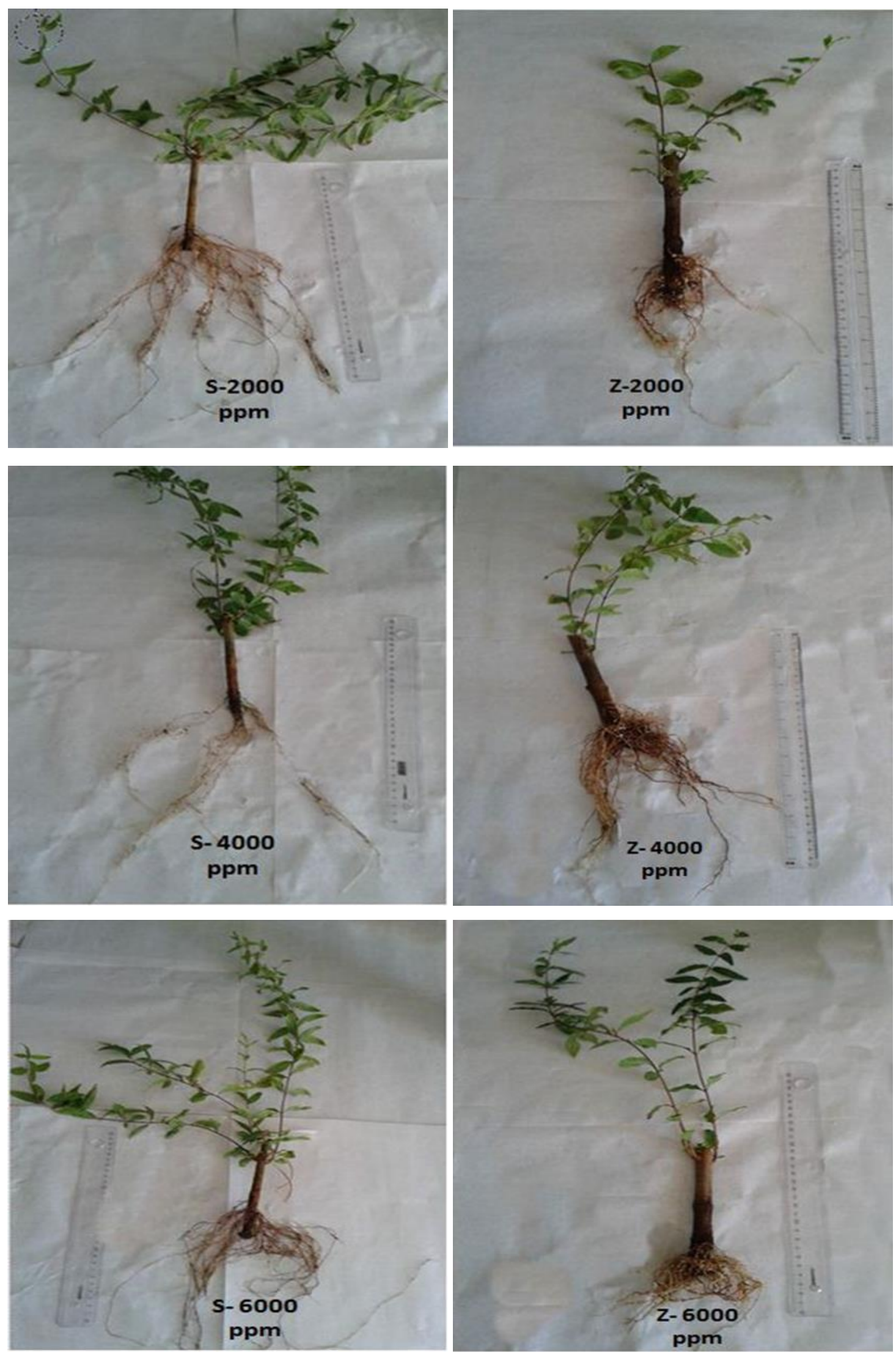

Figure 6. Root and shoot views of the cuttings (2000\&4000\&6000 ppm IBA doses)

APPLIED ECOLOGY AND ENVIRONMENTAL RESEARCH 18(1):201-217.

http://www.aloki.hu • ISSN 15891623 (Print) •ISSN1785 0037 (Online)

DOI: http://dx.doi.org/10.15666/aeer/1801_201217

(c) 2020, ALÖKI Kft., Budapest, Hungary 
Acknowledgements. This article is a part of Master Thesis belonging to Khabbat H. AL-JABBARI.

\section{REFERENCES}

[1] Abu-Zahra, T. R., Al-Shadaideh, A. N., Abubaker, S. M., Qrunfleh, I. M. (2013): Influence of auxin concentrations on different ornamental plants rooting. - International Journal of Botany 9(2): 96-99.

[2] Adekola, O. F., Akpan, I. G. (2012): Effects of growth hormones on sprouting and rooting of Jatropha Curcas L. Stem Cuttings. - J. Appl. Sci. Environ. 16(1): 165-168.

[3] Alikhani, L., Ansari, K., Jamnezhad, M., Tabatabaie, Z. (2011): The effect of different mediums and cuttings on growth and rooting of pomegranate cuttings. - Iranian Journal of Plant Physiology 1(3): 199-203.

[4] Ansari, K. (2013): Effects of different collecting time and different medium on rooting of pomegranate Malas Torsh Cv. cuttings. - Bull. Env. Pharmacol. Life Sci 2(12): 164-168.

[5] Babaie, H., Zarel, K., Nikde, K., Firoozjai, M. N. (2014): Effect of different concentrations of IBA and time of taking cutting on rooting, growth and survival of. Notulae Scientia Biologicae 6(2): 163-166.

[6] Chandra, R., Marathe, R. A., Kumar, P. (2006): Present status of pomegranate and its scope for crop diversification in arid and semi-arid region of Maharashtra. - In: Proceedings of the National Symposium on Agro-forestry for Livelihood Security Environment Protection and Biofuel Production, Jhansi, India, pp. 77-78 (Abstract).

[7] Chandra, R., Marathe, R. A., Jadhav, V. T., Sharma, K. K., Dhinesh Babu, K. (2008): Appraisal of constraints of pomegranate cultivation in Karnataka (Punica granatum L.). In: Proceedings of the 3rd Indian Horticulture Congress: New R\&D Initiatives in Horticulture for Accelerated Growth and Prosperity, Orissa, India, p. 252 (Abstract).

[8] Chandra, R., Meshram, D. T. (2010): Pomegranate culture in Deccan plateau of India. In: Chandra, R. (ed.) Pomegranate. Fruit Veg. Cereal Sci. Biotechnol. 4, Special Issue 2: 113-119.

[9] El-Agamy, S. Z., Mostafa, R. A. A., Shaaban, M. M., El-Mahdy, M. T. (2009): In vitro propagation of manfalouty and nab elgamal pomegranate cultivars research. - J. Agric. Biol. Sci. 5(6): 1169-1175.

[10] Fouda, R. A., Schmidt, G. (1995): Histological changes in the stems of some rosa species propagated by leafy cuttings as affected by IBA treatments. - I.Acta Agronomica Hungarica (43): 265-276.

[11] Frey, B., Hagedorn, F., Gludici, F. (2006): Effect of girdling on soil respiration and root composition in sweet chestnut forest. - For. Ecol. Manage. 225(1-3): 271-277.

[12] Ghosh, D., Bamdyopadhyay, A., Sen, S. K. (1988): Effect of NAA and IBA on adventitious root formation in stem cuttings of pomegranate (Punica granatum L.) under intermittent mist. - Indian Agriculturist 32(4): 239-243.

[13] Gupta, V. N., Banerj, B. K., Datta, S. K. (2002): Effect of auxin on rooting and sprouting behaviour of stem cuttings of Bougainvillea under mist. - Haryana J. Hort. Sci. (31): 4244.

[14] Hansen, J. (1986): Influence of cutting position and stem length on rooting of leaf-bud cuttings of Schefflera arboricola. - Scientia horticulturae 28(1): 177-186.

[15] Hartmann, H. T., Kester, D. F. (1983): Plant propagation principles and practices. $-4^{\text {th }}$ edt., Prentice hall, inc. Engle wood cliffs. New Jersey: 256-303, 676-678 and 727.

[16] Hartmann, H. T., Kester, D. E., Davies, F. T. Jr., Geneve, R. L. (1997): Plant propagation: principles and practices. $-6^{\text {th }}$ edt., Prentice hall of India Private Ltd., New Delhi, India.

[17] Hedge, N. K., Sulikeri, G. S. (1989): Effect of indole butyric acid (IBA) on the rooting of air layers of pomegranate. - Curr. Res. Univ. Agric. Sci., Bangalore 18(11): 161-162.

[18] Janick, J. (1972): Horticultural Science (2nd ed.). - W. H. Freeman and Co., San Francisco, USA. 586 p. 
[19] Janner, R. Y. (2012): Pomegranate (1st Ed.) - Clemson University Press. USA.

[20] Kahlon, P. S. (2007): Studies on the propagation of pomegranate as influenced by season and shoot portion. - Asian Journal of Horticulture 2(1): 6-8.

[21] Kavakl1, Ş., Zainal, A. A., Hepaksoy, S. (2011): Shield against cancer: pomegranate. The abstract book of the Turkish VI. national horticulture congress. 4-8 October 2011. Şanliurfa, pp 807-811.

[22] Kotwal, G. J. (2007): Genetic diversity-independent neutralization of pandemic viruses (e.g. HIV), potentially pandemic (e.g. H5N1 strain of influenza) and carcinogenic (e.g. $\mathrm{HBV}$ and $\mathrm{HCV}$ ) viruses and possible agents of bioterrorism (variola) by enveloped virus neutralizing compounds (EVNCs). - Vaccine 26: 3055-3058.

[23] Mehraj, H., Shiam, I. H., Taufique, T., Shahrin, S., Uddin, A. J. (2013): Influence of Indole-3-Butyric Acid (IBA) on sprouting and rooting potential of Bougainvilleaspectabilis cuttings. - Bangladesh Research Publications Journal 9(1): 4449.

[24] Melgarejo, P., Martinez, R. (1989): Pomegranate. - Official College of Agricultural Engineering Press. Valencia, Spain. 111p (In Spanish).

[25] Melgarejo, P., Martinez, R. (1992): Pomegranate. - Mundi Press. Madrid,Spain. 163p (In Spanish).

[26] Melgarejo, P., Martinez, J., Amoros, A., Martinez, R. (2000): Study of the rooting capacity of ten pomegranate clones (Punica granatum L.). - Adv. Res. Tech. 1: 253-259.

[27] Melgarejo, P., Martinez, J., Martine, J. J., Sanchez, M. (2008): Preliminary Survival Experiments in Transplanting Pomegranate. - In: Production, Processing and Marketing of Pomegranate in the Mediterranean Region: - Advances in Research and Technology. Europe: CIHEAM Publication: 163-167.

[28] Miguel, M., Neves, G., Antunes, M. D. (2010): Pomegranate (Punica granatum L.): A medicinal plant with myriad biological properties-A short review. - J Med Plants Res (4): 2836-2847.

[29] Narin, S., Watna, S. (1983): Effect of IBA on root formation of stem cuttings of purging nut, Jatropha curcas (in Thailand). - Faculty of agriculture, Department of Horticulture, Kasetsart University of Bangkok, Thailand: 1-19.

[30] Onur, C. (1983): Selection of mediterranean region pomegranate ( $\mathrm{PhD}$ Thesis). - Alata Horticulture Research and Training Center. Publication No: 46, Mersin.

[31] Owais, S. J. (2010): Rooting response of five pomegranate varieties to Indole butyric acid concentration and cuttings age. - Pakistan journal of biological sciences 13(2): 51-58.

[32] Özgüven, A. I., Yılmaz, C. (2000): Pomegranate growing in Turkey. - I. Int. Symp. on pomegranate, 15-17 October, Orihuela (Alicante) Spain: 41-48.

[33] Polat, A. A., Çalışkan, O. (2009): Effect of indol butyric acid (IBA) on the rooting cutting in various pomegranate genotypes. - Acta. Hortic. (ISHS) 818: 187-192.

[34] Raj, D., Kanwar, K. (2010): In vitro regeneration of (Punica granatum L.). Plants from different juvenile explants. - J. Fruit Ornamental Plant Res. 18(1): 5-22.

[35] Ramdayal, P., Gupta, A. K., Saini, R. S., Sharma, J. R. (2001): Effect of auxin on the rooting of cutting in Bougainvilleavar Mary Palmer. - Haryana J. Hort. Sci. 30: 215-216.

[36] Reddy, M. K., Gupta, S. K., Jacob, M. R., Khan, S. I., Ferreira, D. (2007): Antioxidant, mantimalarial and antimicrobial activites of tannin-rich fractions, elagitannins and phenolic acids from Punica granatum L. - Planta Medica 73: 461-467.

[37] Saroj, P. L., Awasthi, O. P., Bhargava, R., Singh, U. V. (2008): Standardization of Pomegranate propagation by cutting under mist system in hot arid region. - Indian J. Horti. 65(1): 25-30.

[38] Schubert, S. Y., Lansky, E. P., Neeman, I. (1999): Antioxidant and eicosanoid enzyme inhibition properties of pomegranate seed oil and fermented juice flavonoids. - Journal of Ethnopharmacology 66: 11-17. 
[39] Schwartz, E., Glazer, I., Bar-Yaakov, I., Matityaha, I., Bar-Ilan, I., Holland, D., Amir, R. (2009): Changes in chemical constituents during the maturation and ripening of two commercially important pomegranate accessions. - Food Chemistry 115: 965-973.

[40] Sharma, A., Chandraker, S., Patel, V. K., Ramteke, P. (2009): Anti bacterial activity of medicinal plants against pathogens causing complicate durinary tract infections. - Indian J. Pharm. Sci. 71: 136-139.

[41] Silva, J. A. T., Rana, T. S., Narzary, D., Verma, N., Meshram, D. T., Ranade, S. A. (2013): Pomegranate biology and biotechnology: A review. - Scientia Horticulturae 160: $85-107$

[42] Singh, B. (2009): Influence of planting time and IBA on rooting and growth of pomegranate "Ganesh" Cuttings. - Second international symposium on pomegranate and minor fruit.

[43] Singh, B., Singh, S., Singh, G. (2011): Influence of planting time and IBA on rooting and growth of pomegranate (Punica granatum L.) 'Ganesh'Cuttings. - Acta horticulturae 890: 183.

[44] Singh, K. K. (2014): Effect of IBA concentrations on the rooting of pomegranate (Punica granatum L.) cv. Ganesh hardwood cuttings under mist house condition. - Plant Archives 14(2): 1111-1114.

[45] Singh, K. K., Choudhary, T., Kumar, P., Rawat, J. M. S. (2014): Effect of IBA for inducing rooting in stem cuttings of Duranta golden. - HortFlora Res. Spectrum 3(1): 7780 .

[46] Singh, K. K., Chauhan, J. S., Rawat, J. M. S., Rana, D. K. (2015): Effect of different growing conditions and various concentrations of IBA on the rooting and shooting of hardwood cutting of phalsa (Grewiaasetical.) under valley condition of Garhwal Himalayas. - Plant Archives 15(1): 131-136.

[47] Usanmaz, S., Kahramanoğlu, I., Yılmaz, N. (2014): Yield and pomological characteristics of three pomegranate (Punica granatum L.) cultivars: wonderful, Acco and Herskovitz. Am J Agric For (2): 61-65.

[48] Young, J. (2012): The best time to plant pomegranate cutting. - eHow.com. 